\title{
Visually Induced Analgesia: Seeing the Body Reduces Pain
}

\author{
Matthew R. Longo, ${ }^{1}$ Viviana Betti, ${ }^{2,3}$ Salvatore M. Aglioti, ${ }^{2,3}$ and Patrick Haggard ${ }^{1}$ \\ ${ }^{1}$ Institute of Cognitive Neuroscience, University College London, London WC1N 3AR, United Kingdom, ${ }^{2}$ Dipartimento di Psicologia, Università degli studi \\ di Roma "La Sapienza," I-00185 Rome, Italy, and 'Instituto di Ricovero e Cura a Carattere Scientifico Fondazione Santa Lucia, I-00179 Rome, Italy
}

Given previous reports of strong interactions between vision and somatic senses, we investigated whether vision of the body modulates pain perception. Participants looked into a mirror aligned with their body midline at either the reflection of their own left hand (creating the illusion that they were looking directly at their own right hand) or the reflection of a neutral object. We induced pain using an infrared laser and recorded nociceptive laser-evoked potentials (LEPs). We also collected subjective ratings of pain intensity and unpleasantness. Vision of the body produced clear analgesic effects on both subjective ratings of pain and the N2/P2 complex of LEPs. Similar results were found during direct vision of the hand, without the mirror. Furthermore, these effects were specific to vision of one's own hand and were absent when viewing another person's hand. These results demonstrate a novel analgesic effect of non-informative vision of the body.

\section{Introduction}

Several sensory systems carry information about the body to the brain; the body is a multisensory object, par excellence. Most previous multisensory research has focused on fusion of "events" across modalities (Ernst and Banks, 2002) or on how events in one modality bias other modalities (Jousmäki and Hari, 1998). A less-studied type of interaction involves a continuous "context" in one modality shaping perception of events in another modality. One such context is simply viewing one's own body, which increases tactile spatial acuity (Kennett et al., 2001), accelerates tactile reactions (Tipper et al., 1998), and modulates somatosensory evoked-potentials (SEPs) (Taylor-Clarke et al., 2002). These effects require the visual content of one's own body but not any visual event. The generality of such effects, however, is unknown, having been investigated exclusively for touch. Here, we investigated the effects of seeing the body on the perception and neural processing of pain.

How might seeing the body affect pain? Contextual modulation has long been understood as an organizing principle of neural pain pathways (cf. Melzack and Wall, 1965). However, modulation from seeing one's body could involve either enhancement or inhibition. If enhancing effects observed previously for touch apply across somatic modalities, increases in perceived pain and laser-evoked potentials (LEPs) might be expected. However, many intermodal interactions involving pain are inhibitory. Touch reduces both pain levels (Wall and Sweet, 1967; Higgens et al., 1971) and cortical pain processing (Lundeberg, 1985; Inui et al., 2006). Chronic pain is associated with reduced

Received June 29, 2009; revised July 28, 2009; accepted Aug. 16, 2009.

This work was supported by Biotechnology and Biological Sciences Research Council (BBSRC) Grant BB/ D009529/1, a BBSRC International Scientific Interchange Scheme collaboration grant (P.H., S.M.A.), a Leverhulme Trust Research Fellowship (P.H.), a grant from the Ministero dell'Istruzione, dell'Università, e della Ricerca and Ministero della Sanità, Italy (S.M.A.), and Short-Term Scientific Mission of European Science Foundation Cooperation in Science and Technology Action BM0605 (V.B.). We thank Dr. Laura Cerone for her help with data collection.

Correspondence should be addressed to Matthew R. Longo, Institute of Cognitive Neuroscience, University College London, 17 Queen Square, London WC1N 3AR, UK. E-mail:m.longo@ucl.ac.uk.

DOI:10.1523/JNEUROSCI.3072-09.2009

Copyright $\odot 2009$ Society for Neuroscience ～0270-6474/09/2912125-06\$15.00/0 tactile sensitivity on the affected region (Moriwaki and Yuge, 1999) and reduced size of the corresponding primary somatosensory cortex (SI) tactile representation (Maihöfner et al., 2003; Pleger et al., 2006). Conversely, tactile discrimination training reduces chronic central pain (Flor et al., 2001; Moseley et al., 2008b), an effect enhanced by seeing the body (Moseley and Wiech, 2009). In each case, touch and pain appear antagonistic, suggesting that vision of the body might have different effects on touch and pain. Furthermore, seeing someone else's hand in pain reduces early cortical pain processing (Valeriani et al., 2008). However, the effects of seeing one's own body on nociception are unknown.

We investigated how vision of one's hand affects perception of infrared laser-induced pain and associated cortical processing. Laser stimulation selectively activates thin nociceptive A $\delta$ and C-fibers without activating mechanoreceptive afferents (Treede et al., 2003), creating a pure pain sensation, without touch. We used the mirror box technique (Ramachandran et al., 1995) to create the illusion that the participant's left hand reflected in a mirror aligned with their sagittal plane was actually a direct view of their stimulated right hand. In a control condition, participants saw the mirror image of a non-hand object. The mirror box provides an elegant experimental means of manipulating vision of the body while keeping vision non-informative about stimulation and has been used for this reason previously (Harris et al., 2007; Longo et al., 2008a; Moseley and Wiech, 2009). We measured subjective ratings of pain intensity and unpleasantness, using a visual-analog scale (VAS) and cortical processing using LEPs.

\section{Materials and Methods}

Three experiments were conducted. Experiment 1 used the mirror box to investigate the effects of non-informative vision of the body on pain perception. Participants in experiment 1 experienced pain on their hand but did not see any visual stimulus appearing to cause it, potentially generating perceptual conflict. Experiment 2 addressed whether this conflict was responsible for reduced pain. Now participants looked directly at either their hand or the object. The laser stimulator wand and the red visual laser spot on the hand during actual stimulation were now 
visible in the view hand condition, eliminating any intersensory conflict. Experiment 3 investigated whether visually induced analgesia was specific to viewing one's own hand or would be similarly elicited by viewing another person's hand.

Participants. Thirty healthy volunteers ( 18 female) between 18 and 34 years old (mean $\pm \mathrm{SD}, 24.6 \pm 3.7$ years) participated ( $n=14$ for experiment $1 ; n=16$ for experiment 2, 12 of whom also participated in experiment 3) for payment. Participants were predominantly righthanded (Edinburgh Inventory; mean $\pm \mathrm{SD}, 74.3 \pm 33.1$ ). Procedures were approved by the local ethics committee.

Procedure. In experiment 1, participants looked into a mirror aligned with their parasagittal plane. Their right hand was behind the mirror (index finger $20 \mathrm{~cm}$ from mirror). A baffle extending above the mirror and a black smock worn by the participant prevented vision of the stimulated right hand and arm. In the "view hand" condition, the participant's left hand was placed in front of the mirror (index finger $20 \mathrm{~cm}$ from mirror). Thus, participants saw what appeared to be their right hand (but was in fact the reflected left hand), at the location where their right hand felt to be (Fig. 1). In the "view object" condition, a small brown book $(12.50 \times 18.50 \times 2.40 \mathrm{~cm})$ was placed in approximately the same position, and the nonstimulated left hand rested on the left leg below the table. In both conditions, participants were instructed to gaze into the mirror and fixate the hand/object. The laser stimulation was applied to the right hand behind the mirror.

There were four experimental blocks, two of each condition, with ABBA counterbalancing (Fig. 2). The first condition was counterbalanced across participants. Each block began with a $60 \mathrm{~s}$ induction period of passive looking at the hand or object. Then 30 laser pulses were applied to the dorsum of the right hand. To avoid nociceptor sensitization, the laser was moved randomly between pulses. At least $7 \mathrm{~s}$ elapsed between pulses. Participants rated pain intensity and unpleasantness after each pulse, using a 101-point VAS in which 0 corresponded to no pain and 100 to the worst pain imaginable.

A questionnaire was administered after each block. The items (translated from Italian) were as follows: (1) "It felt like I was looking directly at my hand rather than at a mirror image."; (2) "It felt like the hand I was looking at was my hand."; (3) Did it seem like the hand you saw was a right hand or a left hand?" Item 1 was given after both conditions, items 2 and 3 only in the hand condition. For items 1 and 2, participants rated their agreement using a 7-point Likert scale, +3 indicating "strongly agree", -3 "strongly disagree", and 0 "neither agree nor disagree," although any intermediate value could be used. Values above 0 indicate agreement, whereas values below 0 indicate disagreement. Agreement or disagreement was tested by comparing the mean score with 0 using $t$ tests. Item 3 required dichotomous responses, after which participants indicated the strength of the feeling that the hand was a right/left hand using the VAS. Right hand responses were coded positively, left hand responses negatively, yielding scores between -100 (strong left hand) to +100 (strong right hand).

Experiment 2 was similar to experiment 1 except that the mirror was removed and participants looked either directly at their stimulated right hand or at the object. In the object condition, the object was placed next to the hand, and a cardboard baffle was placed between the hand and the object, occluding direct view of the hand. As the laser stimulator projected a red laser dot onto the hand, a laser pointer was held above the object, projecting a similar red laser light. In the hand condition, the object was removed, and the baffle was moved behind the hand. The questionnaire regarding visual experience was omitted. The first four participants in experiment 2 made VAS ratings after each 10 trials rather than every trial. To reduce habituation effects, experiments 2 and 3 were preceded by 10 laser pulses.

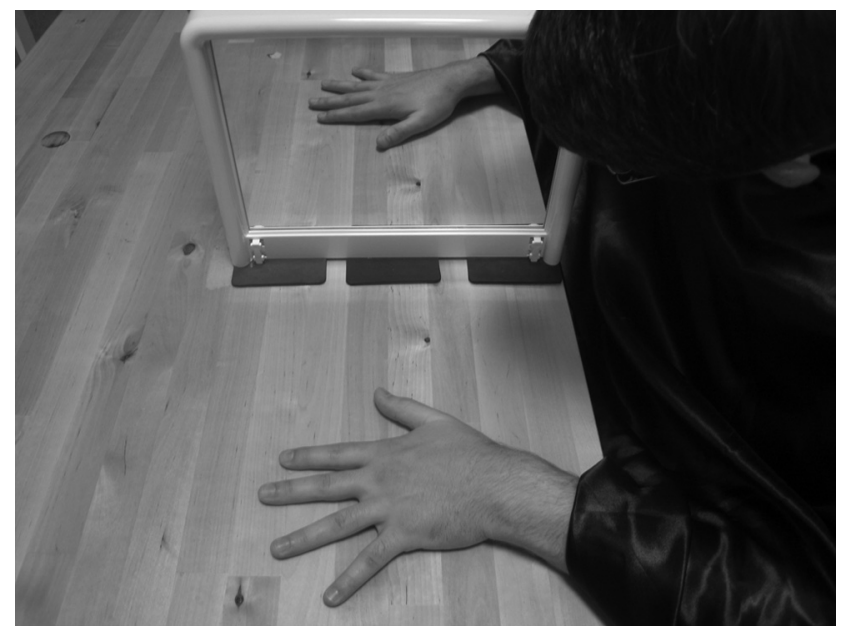

Figure 1. The mirror box technique in which the subject has the experience of viewing their right hand, while in fact seeing their left hand reflected in a mirror.
Figure 2. Schematic depiction of experimental setups. Apparent line of sight depicted with dashed line, actual line of sight with Experiment 2

xperiment 1

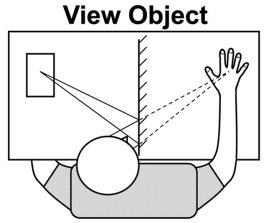

Experiment 3 View Object
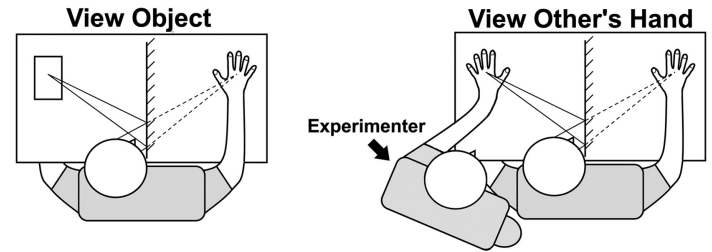

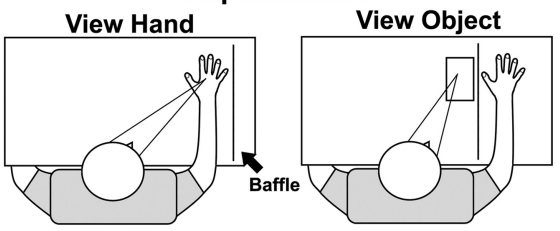

(1)

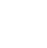

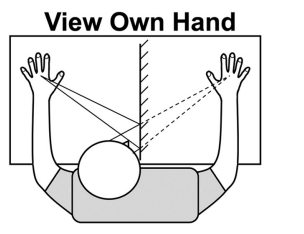

Experin

Experiment 3 was similar to experiment 1 with the addition of a condition in which participants saw the mirror reflection of an experimenter's hand. Thus, participants viewed the mirror reflection of (1) their own hand, (2) the object, or (3) somebody else's hand (an experimenter's). The experimenter was seated next to the participant with their left hand positioned in the location that the subject's hand had occupied in experiment 1 . Thus, participants gazing into the mirror had the visual experience of another person's right hand appearing in first-person perspective at the location where their own right hand felt to be. The participant's left hand remained in their lap. No attempt was made to disguise the presence of the experimenter or to make their hand physically resemble the participant's hand. There was a single block of each condition, the order of which was counterbalanced across participants.

Pain stimuli were delivered with an infrared neodymium yttrium aluminum perovskite laser (EL.EN. Group). Pulse duration and intensity were adjusted for each participant to the minimum values eliciting clear sensations of pain (laser pulses; intensity, 1.5-3.25 J; duration, 2-4 ms; diameter, 4-5 mm; wavelength of $1.34 \mu \mathrm{m}$ ).

Electroencephalographic recording. A SynAmp amplifiers system and Scan 4.3 software (Neuroscan) were used to record electroencephalographic (EEG) data. Recordings were obtained from 54 scalp electrodes in experiment 1 and 60 in experiments 2 and 3. Horizontal electrooculogram was recorded bipolarly from electrodes placed on the outer canthi of each eye, and vertical electrooculogram was recorded from an electrode below the right eye. Reference was at the nose and ground at AFz. Electrode impedances were kept below $5 \mathrm{~K} \Omega$. EEG signals were amplified and digitized at $1000 \mathrm{~Hz}$. 

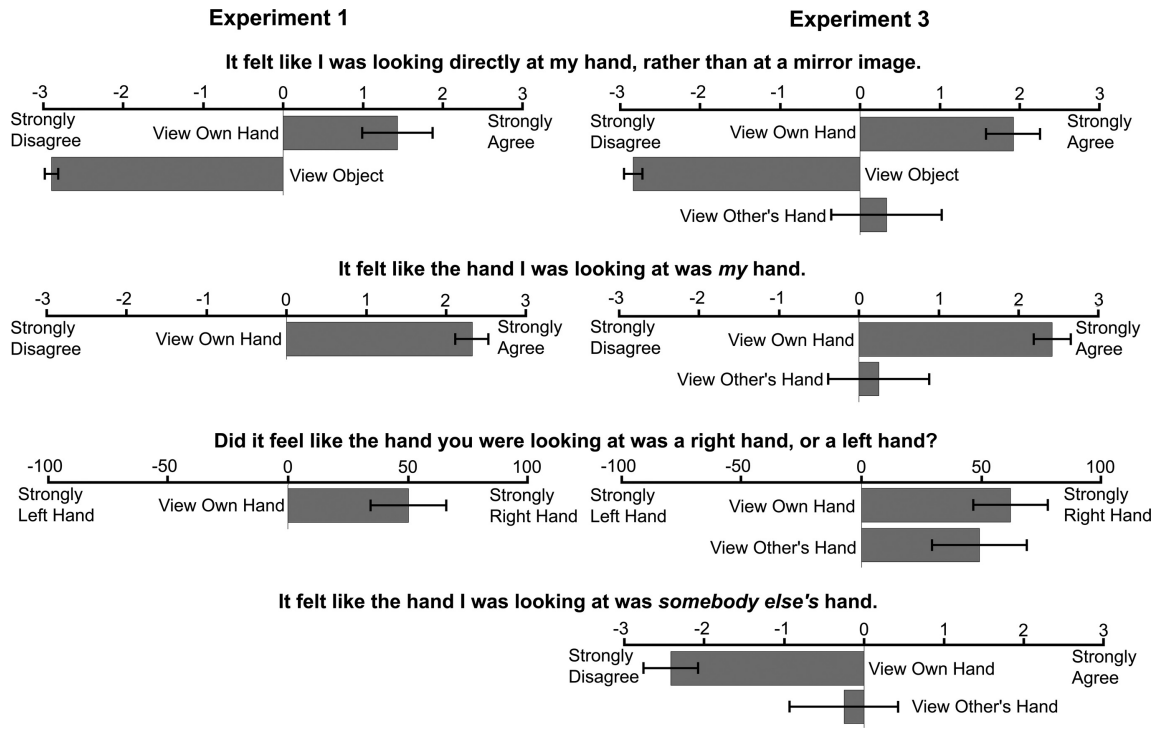

Figure 3. Subjective report data from experiment 1 (left) and experiment 3 (right). Error bars are one SEM.

\section{Results}

\section{Experiment 1}

Illusion questionnaire

Participants agreed that "It felt like I was looking directly at my hand rather than at a mirror image" after seeing their hand (i.e., the mean score was significantly $>0$; $\left.t_{(13)}=3.26, p<0.01\right)$ but disagreed after seeing the object $\left(t_{(13)}=-37.39, p<\right.$ 0.0001 ) (Fig. 3). In the hand condition, participants agreed that "It felt like the hand I was looking at was mine" $\left(t_{(13)}=\right.$ $11.59, p<0.0001)$ and felt like they were looking at a right (rather than a left) hand $\left(t_{(13)}=3.21, p<0.01\right)$. Thus, the mirror box effectively created the illusion of looking directly at the right hand in the hand, but not the object, condition.

\section{Subjective ratings of pain}

Seeing the hand reduced pain intensity $\left(F_{(1,12)}=8.07, p<0.02\right)$ (Fig. 4) and unpleasantness $\left(F_{(1,12)}=5.58, p<0.05\right)$.

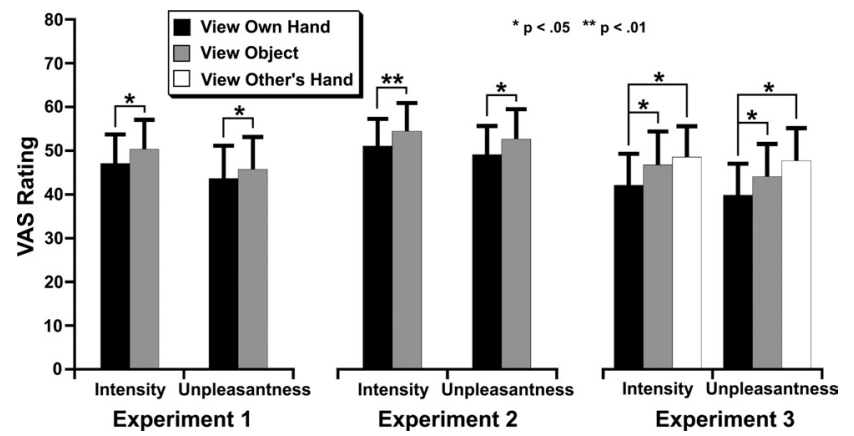

Figure 4. Subjective ratings of pain intensity and unpleasantness in the three experiments. Error bars are one SEM.

Data analysis. EEG data were analyzed with EEGLAB (Delorme and Makeig, 2004) in Matlab 7.3 (MathWorks). Data were digitally filtered with a bandpass of $0.3-30 \mathrm{~Hz}$ and segmented into epochs time locked to laser pulses ( -500 to $1000 \mathrm{~ms}$ ). Baseline was calculated from the $200 \mathrm{~ms}$ preceding the pulse. Visual inspection of epoched data was used to remove trials with obvious contamination by ocular movements. Additional correction of ocular artifacts was performed using blind source separation with independent components analysis (Jung et al., 2000) on epoched data. To reduce effects of pain habituation (Ernst et al., 1986; Milne et al., 1991; Valeriani et al., 2003), the first 10 trials of the experiment were eliminated, and counterbalance order was included as a between-subjects factor in ANOVAs to exclude variance attributable to habituation (supplemental data, available at www.jneurosci.org as supplemental material).

Two LEP components were investigated. First, the early, lateralized N1 potential, maximal over contralateral temporal electrodes, and originating from operculoinsular cortex (Garcia-Larrea et al., 2003), possibly including secondary somatosensory cortex (Spiegel et al., 1996; Frot et al., 1999). Second, the bipolar vertex N2/P2 complex. Intracranial recordings have linked the N2/P2 to parallel activations in at least three brain areas: SI, parasylvian, and cingulate cortices (Ohara et al., 2004). $\mathrm{N} 1$ peaks were computed as the minimum value at $\mathrm{T} 7$ re-referenced to $\mathrm{Fz}$ between 130 and $210 \mathrm{~ms}$. N2 and $\mathrm{P} 2$ peaks were computed, respectively, as the minimum value at $\mathrm{Cz}$ between 170 and $240 \mathrm{~ms}$ and the maximum value at $\mathrm{Cz}$ between 300 and $450 \mathrm{~ms}$. N2/P2 amplitude was computed as the difference between $\mathrm{P} 2$ and $\mathrm{N} 2$ peaks.
These reductions were strongly correlated across individuals $\left(r_{(13)}=0.92, p<0.0001\right)$.

Laser-evoked potentials

Seeing the hand also reduced N2/P2 amplitude $\left(F_{(1,12)}=28.83\right.$, $p<0.001$ ) (Fig. 5). No significant modulation of the N1 component was observed (mean $\pm \mathrm{SD}$ : hand, $-7.4 \pm 4.3 \mu \mathrm{V}$ object, $\left.-6.7 \pm 2.5 \mu \mathrm{V} ; F_{(1,12)}=0.88\right)$.

There were significant correlations between the analgesic effects of seeing the hand on N2/P2 amplitude and subjective reports of both pain intensity $\left(r_{(13)}=0.72, p<0.005\right)$ and unpleasantness $\left(r_{(13)}=0.61, p<0.02\right)$.

\section{Experiment 2}

Subjective ratings of pain

Seeing the hand significantly reduced pain intensity $\left(F_{(1,14)}=\right.$ 9.60, $p<0.01)$ and unpleasantness $\left(F_{(1,14)}=7.56, p<0.02\right)$ (Fig. $4)$. The two measures were again strongly correlated across participants $\left(r_{(15)}=0.73, p<0.001\right)$.

\section{Laser-evoked potentials}

Seeing the hand again significantly reduced N2/P2 amplitude $\left(F_{(1,14)}=5.82, p<0.05\right)$ (Fig. 5). No significant modulation of the N1 was observed (mean $\pm \mathrm{SD}$ : hand, $-9.6 \pm 4.8 \mu \mathrm{V}$; object, $\left.-9.3 \pm 4.6 \mu \mathrm{V} ; F_{(1,14)}=0.21\right)$.

Correlations between the analgesic effects on subjective ratings of pain and N2/P2 amplitude were in the same direction as in experiment 1 but did not reach statistical significance for either pain intensity $\left(r_{(15)}=0.32, p=0.21\right)$ or unpleasantness $\left(r_{(15)}=\right.$ $0.46, p=0.06)$.

\section{Experiment 3}

One participant showed highly unstable subjective pain ratings, with a progressive escalation of reported pain intensity from 17 in block 1 to 72 in block 3 and was excluded from analyses.

\section{Illusion questionnaire}

Participants on average agreed that "It felt like I was looking directly at my hand rather than at a mirror image" after seeing their hand $\left(t_{(10)}=5.19, p<0.0005\right)$ but not the object $\left(t_{(10)}=\right.$ $-23.12, p<0.0001)$ or the experimenter's hand $\left(t_{(10)}=0.94\right.$, 

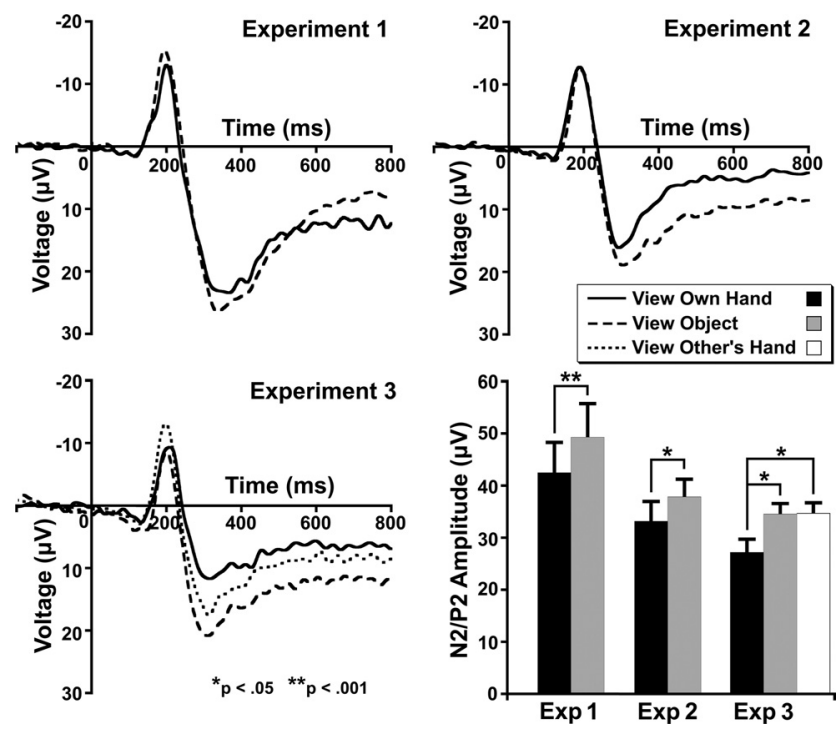

Figure 5. Grand mean LEPs recorded from electrode C $z$ in the three experiments and N2/P2 peak-to-peak amplitudes at $\mathrm{Cz}$ (bottom right). Error bars are one SEM.

NS) (Fig. 3). In the own hand condition, participants agreed that "It felt like the hand I was looking at was mine" $\left(t_{(10)}=9.93, p<\right.$ $0.0001)$ but not when seeing someone else's hand $\left(t_{(10)}=0.90\right.$, NS). Participants reported that it felt like they were looking at a right (rather than a left) hand when seeing both their own hand $\left(t_{(10)}=3.63, p<0.005\right)$ and someone else's hand $\left(t_{(10)}=2.17\right.$, $p=0.055)$. Participants disagreed that "It felt like I was looking at somebody else's hand" when looking at their own hand $\left(t_{(10)}=\right.$ $-6.50, p<0.0001$ ) but not when seeing the other person's hand $\left(t_{(10)}=-0.82\right.$, NS). Therefore, the mirror box produced the illusion of looking at one's own right hand in the view hand condition but not when viewing the experimenter's hand.

\section{Subjective ratings of pain}

There was a significant main effect of condition on both pain intensity $\left(F_{(2,20)}=5.00, p<0.05\right)$ and unpleasantness $\left(F_{(2,20)}=\right.$ $4.79, p<0.05$ ) (Fig. 4). Seeing one's own hand was analgesic relative to seeing the object, both for pain intensity $\left(t_{(10)}=\right.$ -3.07, $p<0.02)$ and unpleasantness $\left(t_{(10)}=-2.70, p<0.05\right)$. Similar reductions were also observed when seeing one's own hand relative to seeing someone else's hand (intensity, $t_{(10)}=$ $-2.53, p<0.05$; unpleasantness, $\left.t_{(10)}=-2.55, p<0.05\right)$. The object and other hand conditions did not differ significantly for either intensity $\left(t_{(10)}=0.83\right)$ or unpleasantness $\left(t_{(10)}=1.34\right)$. These results suggest that the analgesic effects of seeing a hand are specific to viewing one's own hand.

\section{Laser-evoked potentials}

There was a significant effect of condition on N2/P2 amplitude $\left(F_{(2,20)}=4.74, p<0.05\right)$ (Fig. 5). Amplitude was reduced when seeing one's own hand compared with the object $\left(t_{(10)}=-2.63\right.$, $p<0.05)$ and someone else's hand $\left(t_{(10)}=-2.62, p<0.05\right)$. There was no difference between the object and other hand conditions $\left(t_{(10)}=0.05\right)$. There was no effect of condition on N1 amplitude (mean $\pm \mathrm{SD}$ : own hand, $-7.31 \pm 4.4 \mu \mathrm{V}$; other hand, $-8.0 \pm 3.5 \mu \mathrm{V}$; object, $\left.-6.95 \pm 3.8 \mu \mathrm{V} ; F_{(2,10)}=0.48\right)$.

\section{Discussion}

These results demonstrate a novel form of visually induced analgesia. Looking at one's hand produced significant reductions of subjective intensity and unpleasantness of laser pain and in the amplitude of the N2/P2 complex of LEPs. These effects were observed both when the illusion of looking directly at the hand was induced with a mirror box (experiments 1 and 3) and when participants viewed their hand directly during stimulation (experiment 2). The reduction was specific to seeing one's own hand (experiment 3). Previous studies have suggested that vision of the body may reduce chronic phantom limb pain (Ramachandran and Rogers-Ramachandran, 1996; Chan et al., 2007) and also that seeing someone else's body in pain induces a specific reduction of early LEPs (Valeriani et al., 2008). The present data show an analgesic effect of seeing the body, not tied to the specific case of phantom limbs, and operating on acute stimulus-generated pain. Thus, we show that viewing the body not only induces plasticity in the cortical representations within which pain signals are processed but also modulates perceptual processing of individual pain events.

Valeriani et al. (2008) recently found that empathy for others' pain attenuates the early, lateralized N1/P1 complex of LEPs, without affecting subjective pain ratings. In contrast, the present results demonstrate that seeing one's own hand attenuates the later, vertex N2/P2 complex with corresponding subjective attenuation. This divergence between early and late LEPs suggests that our visual effect and their empathic effect may have qualitatively different neuronal bases. The absence of modulation of the N1 in the present study raises the possibility that the effects of seeing one's hand operate via modulation of evaluative and affective, rather than purely sensory, components of the pain matrix. However, sensory and affective components of pain tend to be strongly correlated, so the relation between the results of Valeriani et al. and ours remains unclear.

Our findings suggest a reliable attenuation of pain systems for viewing the body. These findings suggest several possible theoretical interpretations. We first considered the theory that conflict between visual and proprioceptive representations could induce visual analgesia. However, experiment 2 showed similar results when conflict-inducing mirrors were not used, contrary to this theory. An alternative theory links the analgesic effect to a sense of body ownership. The experience of viewing one's own body contains multiple dissociable elements (Longo et al., 2008b), including the senses of ownership (i.e., that it is my body) and agency (i.e., that I am in control of my body). It is currently unclear which aspect of seeing the hand is responsible for the present effects. One previous study found that the enhancing effect of seeing one's body on touch was linked primarily to sense of ownership (Longo et al., 2008a). In contrast, other effects, such as acceleration of visual reaction times (Longo and Haggard, 2009) and proprioceptive integration (Tsakiris et al., 2006), appeared to be related to agency. It is well established that perceived control reduces both the subjective experience of (Weisenberg et al., 1985) and neural responses to (Salomons et al., 2004) pain, via modulation of anterolateral prefrontal regions involved in pain appraisal (Wiech et al., 2006). It is therefore possible that our effects are mediated by an increased sense of bodily control when viewing the hand. This could be investigated in future studies in which participants actively move the viewed hand. Alternatively, however, viewing the hand in pain without being able to withdraw it could also very well produce a perceived reduction of control.

\section{Crossmodal inhibition}

Seeing the body has wide-ranging influences on somatosensation. Interestingly, however, the nature of this influence is quite different between touch and pain. Whereas non-informative vi- 
sion of the hand increases the acuity of touch (Kennett et al., 2001) and the amplitude of SEPs (Taylor-Clarke et al., 2002), the present results demonstrate conversely that seeing the hand decreases the subjective experience of pain and the amplitude of LEPs. These opposite effects of seeing the body on touch and pain are consistent with the well-established inhibitory interactions between the two modalities themselves. Given the modality segregation of somatosensory cortex generally (Mountcastle, 1957; Friedman et al., 2004) and of touch and pain specifically (Ploner et al., 2000; Ohara et al., 2004; Chen et al., 2009), tactile and nociceptive representations may stand in competitive relations. Competition between modalities might mimic the well-established competitive relations between adjacent skin regions within a single modality map as a result of lateral inhibition within the cortex (Merzenich et al., 1984).

Could a common mechanism produce such divergent effects on touch and pain? One possibility would be a visually induced crossmodal activation of GABAergic interneurons. Injection of GABA antagonists increases the size of SI tactile receptive fields (Dykes et al., 1984; Alloway et al., 1989), suggesting that GABAergic interneurons function to sharpen tactile receptive fields, increasing tactile acuity. Conversely, GABA agonists are effective treatments for chronic central pain (Canavero and Bonicalzi, 1998), suggesting that reduced GABAergic inhibition may be a major cause of chronic pain. Consistent with this interpretation, patients with complex regional pain syndrome show reduced intracortical inhibition measured with paired-pulse transcranial magnetic stimulation (TMS) (Schwenkreis et al., 2003), whereas repetitive TMS of motor cortex, known to increase intracortical inhibition, alleviates chronic pain (Lefaucheur et al., 2006).

Both the present results showing analgesic effects of seeing the body and previous findings showing tactile enhancement (Kennett et al., 2001) could therefore be explained by visual modulation of somatosensory GABAergic interneurons. This speculation is supported by multisensory influences on cortical inhibition in other physiological systems. For example, viewing a hand extends the TMS-evoked silent period compared with viewing a fixation cross (Schütz-Bosbach et al., 2009). Furthermore, Dehner et al. (2004) described a GABA-dependent auditory-somatosensory inhibitory effect in cats.

\section{Therapeutic implications}

The present results also have possible therapeutic implications. Several authors have reported that a mirror box similar to that used in our experiment can reduce phantom limb pain (Ramachandran and Rogers-Ramachandran, 1996; Chan et al., 2007) and chronic central pain (McCabe et al., 2003), although replication attempts have been mixed (Brodie et al., 2007; Moseley et al., 2008a). The present results extend these findings in three ways, suggesting that vision of the body (whether with a mirror box or not) may have a broader range of analgesic effects than suspected previously.

First, the present results show an analgesic effect of vision of the body for acute, rather than chronic, pain. Second, several authors have suggested that mirror therapy may operate by promoting plastic reorganization within somatosensory map or by correcting a distorted body image through visual recalibration of proprioception (Ramachandran and Rogers-Ramachandran, 1996; Harris, 1999; Ramachandran and Altschuler, 2009), yet our results demonstrate analgesic effects of seeing the body in healthy participants without body image distortion. Third, previous studies have generally involved voluntary movement of the unaffected limb, inducing the illusion of control over the affected hand. Therapeutic effects are typically attributed to the mirrorinduced match between visually perceived movement and efferent commands specifying movement (Ramachandran and RogersRamachandran, 1996; McCabe et al., 2003). The present results, however, suggest that qualitatively similar analgesic effects may result from simply seeing the hand, independent of movement or match between efferent and afferent signals.

\section{References}

Alloway KD, Rosenthal P, Burton H (1989) Quantitative measurements of receptive field changes during antagonism of GABAergic transmission in primary somatosensory cortex of cats. Exp Brain Res 78:514-532.

Brodie EE, Whyte A, Niven CA (2007) Analgesia through the looking-glass? A randomized controlled trial investigating the effect of viewing a "virtual" limb upon phantom limb pain, sensation and movement. Eur J Pain 11:428-436.

Canavero S, Bonicalzi V (1998) The neurochemistry of central pain: evidence from clinical studies, hypothesis and therapeutic implications. Pain 74:109-114.

Chan BL, Witt R, Charrow AP, Magee A, Howard R, Pasquina PF, Heilman KM, Tsao JW (2007) Mirror therapy for phantom limb pain. N Engl J Med 357:2206-2207.

Chen LM, Friedman RM, Roe AW (2009) Area-specific representation of mechanical nociceptive stimuli within SI cortex of squirrel monkeys. Pain 141:258-268.

Dehner LR, Keniston LP, Clemo HR, Meredith MA (2004) Cross-modal circuitry between auditory and somatosensory areas of the cat anterior extosylvian sulcal cortex: a "new" inhibitory form of multisensory convergence. Cereb Cortex 14:387-403.

Delorme A, Makeig S (2004) EEGLAB: an open source toolbox for analysis of single-trial EEG dynamics including independent component analysis. J Neurosci Methods 134:9-21.

Dykes RW, Landry P, Metherate R, Hicks TP (1984) Functional role of GABA in cat primary somatosensory cortex: shaping receptive fields of cortical neurons. J Neurophysiol 52:1066-1093.

Ernst M, Lee MH, Dworkin B, Zaretsky HH (1986) Pain perception decrement produced through repeated stimulation. Pain 26:221-231.

Ernst MO, Banks MS (2002) Humans integrate visual and haptic information in a statistically optimal fashion. Nature 415:429-433.

Flor H, Denke C, Schaefer M, Grüsser S (2001) Effect of sensory discrimination training on cortical reorganization and phantom limb pain. Lancet 357:1763-1764.

Friedman RM, Chen LM, Roe AW (2004) Modality maps within primate somatosensory cortex. Proc Natl Acad Sci U S A 101:12724-12729.

Frot M, Rambaud L, Guénot M, Mauguière F (1999) Intracortical recordings of early pain-related CO2-laser evoked potentials in the human second somatosensory (SII) area. Clin Neurophysiol 110:133-145.

Garcia-Larrea L, Frot M, Valeriani M (2003) Brain generators of laserevoked potentials: from dipoles to functional significance. Neurophysiol Clin 33:279-292.

Harris AJ (1999) Cortical origin of pathological pain. Lancet 354:14641466.

Harris JA, Arabzadeh E, Moore CA, Clifford CWG (2007) Noninformative vision causes adaptive changes in tactile sensitivity. J Neurosci 27:7136-7140.

Higgens JD, Tursky B, Schwartz GE (1971) Shock-elicited pain and its reduction by concurrent tactile stimulation. Science 172:866-867.

Inui K, Tsuji T, Kakigi R (2006) Temporal analysis of cortical mechanisms for pain relief by tactile stimuli in humans. Cereb Cortex 16:355-365.

Jousmäki V, Hari R (1998) Parchment-skin illusion: sound-biased touch. Curr Biol 8:R190-R191.

Jung TP, Makeig S, Humphries C, Lee TW, McKeown MJ, Iragui V, Sejnowski TJ (2000) Removing electroencephalographic artifacts by blind source separation. Psychophysiology 37:163-178.

Kennett S, Taylor-Clarke M, Haggard P (2001) Noninformative vision improves the spatial resolution of touch in humans. Curr Biol 11:1188-1191.

Lefaucheur JP, Drouot X, Ménard-Lefaucheur I, Keravel Y, Nguyen JP (2006) Motor cortex rTMS restores defective intracortical inhibition in chronic neuropathic pain. Neurology 67:1568-1574.

Longo MR, Haggard P (2009) Sense of agency primes manual motor responses. Perception 38:69-78. 
Longo MR, Cardozo S, Haggard P (2008a) Visual enhancement of touch and the bodily self. Conscious Cogn 17:1181-1191.

Longo MR, Schüür F, Kammers MP, Tsakiris M, Haggard P (2008b) What is embodiment? A psychometric approach. Cognition 107:978-998.

Lundeberg T (1985) Relief of pain from a phantom limb by peripheral stimulation. J Neurol 232:79-82.

Maihöfner C, Handwerker HO, Neundörfer B, Birklein F (2003) Patterns of cortical reorganization in complex regional pain syndrome. Neurology 61:1707-1715.

McCabe CS, Haigh RC, Ring EF, Halligan PW, Wall PD, Blake DR (2003) A controlled pilot study of the utility of mirror visual feedback in the treatment of complex regional pain syndrome (type 1). Rheumatology 42:97-101.

Melzack R, Wall PD (1965) Pain mechanisms: a new theory. Science 150:971-979.

Merzenich MM, Nelson RJ, Stryker MP, Cynader MS, Schoppmann A, Zook JM (1984) Somatosensory cortical map changes following digit amputation in adult monkeys. J Comp Neurol 224:591-605.

Milne RJ, Kay NE, Irwin RJ (1991) Habituation to repeated painful and non-painful cutaneous stimuli: a quantitative psychophysical study. Exp Brain Res 87:438-444.

Moriwaki K, Yuge O (1999) Topographical features of cutaneous tactile hypoesthetic and hyperesthetic abnormalities in chronic pain. Pain 81:1-6.

Moseley GL, Wiech K (2009) The effect of tactile discrimination training is enhanced when patients watch the reflected image of their unaffected limb during training. Pain 144:314-319.

Moseley GL, Gallace A, Spence C (2008a) Is mirror therapy all it is cracked up to be? Current evidence and future directions. Pain 138:7-10.

Moseley GL, Zalucki NM, Wiech K (2008b) Tactile discrimination, but not tactile stimulation alone, reduces chronic limb pain. Pain 137:600-608.

Mountcastle VB (1957) Modality and topographic properties of single neurons in cat's somatic sensory cortex. J Neurophysiol 20:408-434.

Ohara S, Crone NE, Weiss N, Treede RD, Lenz FA (2004) Cutaneous painful laser stimuli evoke responses recorded directly from primary somatosensory cortex in awake humans. J Neurophysiol 91:2734-2746.

Pleger B, Ragert P, Schwenkreis P, Förster AF, Wilimzig C, Dinse H, Nicolas V, Maier C, Tegenthoff M (2006) Patterns of cortical reorganization parallel tactile discrimination and pain intensity in complex regional pain syndrome. Neuroimage 32:503-510.

Ploner M, Schmitz F, Freund HJ, Schnitzler A (2000) Differential organization of touch and pain in human primary somatosensory cortex. J Neurophysiol 83:1770-1776.

Ramachandran VS, Altschuler EL (2009) The use of visual feedback, in par- ticular mirror visual feedback, in restoring brain function. Brain 132:1693-1710.

Ramachandran VS, Rogers-Ramachandran D, Cobb S (1995) Touching the phantom limb. Nature 377:489-490.

Ramachandran VS, Rogers-Ramachandran D (1996) Synaesthesia in phantom limbs induced with mirrors. Proc Biol Sci 263:377-386.

Salomons TV, Johnstone T, Backonja MM, Davidson RJ (2004) Perceived controllability modulates the neural response to pain. J Neurosci 24:7199-7203.

Schütz-Bosbach S, Avenanti A, Aglioti SM, Haggard P (2009) Don't do it! Cortical inhibition and self-attribution during action observation. J Cogn Neurosci 21:1215-1227.

Schwenkreis P, Janssen F, Rommel O, Pleger B, Völker B, Hosbach I, Dertwinkel R, Maier C, Tegenthoff M (2003) Bilateral motor cortex disinhibition in complex regional pain syndrome (CRPS) type I of the hand. Neurology 61:515-519.

Spiegel J, Hansen C, Treede RD (1996) Laser-evoked potentials after painful hand and foot stimulation in humans: evidence for generation of the middle-latency component in the secondary somatosensory cortex. Neurosci Lett 216:179-182.

Taylor-Clarke M, Kennett S, Haggard P (2002) Vision modulates somatosensory cortical processing. Curr Biol 12:233-236.

Tipper SP, Lloyd D, Shorland B, Dancer C, Howard LA, McGlone F (1998) Vision influences tactile perception without proprioceptive orienting. Neuroreport 9:1741-1744.

Treede RD, Lorenz J, Baumgärtner U (2003) Clinical usefulness of laserevoked potentials. Neurophysiol Clin 33:303-314.

Tsakiris M, Prabhu G, Haggard P (2006) Having a body versus moving your body: how agency structures body-ownership. Conscious Cogn 15:423-432.

Valeriani M, de Tommaso M, Restuccia D, Le Pera D, Guido M, Iannetti GD, Libro G, Truini A, Di Trapani G, Puca F, Tonali P, Cruccu G (2003) Reduced habituation to experimental pain in migraine patients: a $\mathrm{CO} 2$ laser evoked potential study. Pain 105:57-64.

Valeriani M, Betti V, Le Pera D, De Armas L, Miliucci R, Restuccia D, Avenanti A, Aglioti SM (2008) Seeing the pain of others while being in pain: a laser-evoked potentials study. Neuroimage 40:1419-1428.

Wall PD, Sweet WH (1967) Temporary abolition of pain in man. Science 155:108-109.

Weisenberg M, Wolf Y, Mittwoch T, Mikulincer M, Aviram O (1985) Subject versus experimenter control in the reaction to pain. Pain 23:187-200.

Wiech K, Kalisch R, Weiskopf N, Pleger B, Stephan KE, Dolan RJ (2006) Anterolateral prefrontal cortex mediates the analgesic effect of expected and perceived control over pain. J Neurosci 26:11501-11509. 